\title{
Design e pós-modernidade
}

\section{RESUMO}

Esse texto procura mostrar a importância das características visuais pós-modernas, como listadas aqui, para a libertação do design contemporâneo de paradigmas restritivos de origem modernista, mostrando que ao invés da continuar seguindo cegamente a filosofia do "less is more" deveríamos explorar a multiplicidade de soluções possíveis, adotando o lema oposto do "the more, the better", já que o design necessita explorar sempre um amplo repertório de alternativas, ao procurar criar soluções originais e inéditas.

\section{PALAVRAS-CHAVE}

design

modernismo

pós-modernismo

\section{ABSTRACT}

This text intends to show the importance of a postmodern visual attitude in graphic design, for it expands the number of new possible solutions. Design needs to get rid of the restrictive modernist belief that "less is more", cultivating instead the idea that "the more, the better", which aims at the development of creative and innovative alternatives, through a great many number of experiments with several of those visual postmodern characteristics listed here.

\section{KEY WORDS}

design

modernism

postmodernism

\section{Flávio Vinicius Cauduro}

Professor do Programa de Pós-Graduação em Comunicação da PUCRS/RS/ $B R$.

flaviocauduro@yahoo.com
Mesmo que o antigo paradigma modernista esteja desaparecendo gradualmente das práticas contemporâneasdedesign, aindaháumafortetendência em muitos dos nossos designers de continuarem adotando modelos de design "modernista" criados no exterior, enquanto negligenciam outras possíveis alternativas de inspiração brasileira, para suas práticas.

Por isso, muitos deles persistem ainda em manter uma atitude autoritária, antidialógica para com seus clientes e público em geral, por não quererem admitir a relatividade de suas crenças e posições (síndrome do designer como único intérprete soberano da modernidade gráfica).

Como lembra a designer gráfica brasileira e educadora Ana Luisa Escorel, que pertence à primeira geração de designers brasileiros, o design gráfico foi introduzido no Brasil, como uma nova atividade profissional, em São Paulo, em meados dos anos cinqüenta, por um grupo de jovens dedicados às artes visuais e criações gráficas. Estavam bem cientes das últimas tendências européias nestas áreas (Escorel, 1987, p. 80), e exibiam uma forte tendência estruturalista nos projetos de design então formulados, observados principalmente nas empresas que adotavam seus rígidos princípios e programas de identidade visual. Seguiam estéticas funcionalistas, construtivistas e do De Stijl, e seus novos códigos gráficos (Escorel, 1987, p. 80). O funcionalismo teve um efeito decisivo sobre aquela primeira geração de designers brasileiros, pois introduzia uma metodologia de projeto sistemática, ao invés de continuar tentando resolver intuitivamente os problemas suscitados pelo desenvolvimento industrial (Escorel, 1987, p. 80).

Assim, seguir as idéias dos modernistas europeus era preferível a buscar inspiração em nosso passado, uma vez que as artes gráficas portuguesas não nos ofereciam naquela época uma alternativa propícia para o desenvolvimento de uma linguagem gráfica brasileira (Escorel,1987, p. 84).

A escola gráfica portuguesa era tradicionalista e considerada naquele tempo situar-se entre as menos inventivas da Europa, em nada comparável às da Alemanha, Suíça, Inglaterra, França e Itália, só para citar as mais influentes daquele tempo. Escorel afirma que "o grosso do trabalho produzido antes do final dos anos 1950 revela uma timidez, claramente determinada pela adoção de conceitos estéticos préindustriais" (Escorel, 1987, p. 84). Critérios e padrões visuais europeus (posteriormente também adotados pelos americanos) eram utilizados para julgar e menosprezar nossas produções gráficas passadas.

Seguindo a ideologia modernista, se acreditava que nosso desenvolvimento gráfico era apenas uma 
questão de adoção de novas crenças e princípios visuais "modernos", juntamente com a substituição de tecnologias gráficas obsoletas, para dar novos rumos às tradicionais e "ineficientes" práticas locais. Por isso, na ausência de uma cultura gráfica brasileira, pensavase que necessitávamos cortar caminho e ganhar tempo procurando pular direto para a utilização de todos os meios de comunicação modernos (Escorel, 1987, p. 84) Muito sintomático, também, era a noção de muitos designers, e que mesmo hoje em dia ainda persiste, de que exista apenas uma cultura brasileira, homogênea e monolítica, orientando nosso design, e que só podia ser aquela de nossas elites, sintonizadas com as mais recentes criações européias e americanas.

\section{0 funcionalismo teve um efeito decisivo sobre a primeira geração de designers brasileiros, pois introduzia uma metodologia de projeto sistemática}

Por falta de tradições em que se aprofundar, fomos obrigados a adotar outros sistemas de referência. Assim, precisamos quase sempre conciliar o moderno com o anacrônico, visto que "uma das principais características da realidade industrial brasileira é a coexistência, lado a lado, de técnicas rudimentares com os mais recentes avanços tecnológicos (Escorel, 1987, p. 156).

Escorel acha que a sensibilidade dos designers gráficos brasileiros vive em sintonia com $\mathrm{o}$ contemporâneo e com o efêmero, traços indicativos da nossa integração atual com a pós-modernidade. E uma noção que se infiltrou na mente de muitos designers brasileiros é a de que a história de nosso design só começa por volta dos anos 60 (Taborda, 1987a, p. 54); um mito que também predomina na publicidade brasileira (Valério, 1987, p. 90).

Gerald Thomas, por isso, acha que o Brasil sofre, entre outras coisas, de amnésia coletiva, como se pode observar com muitos outros jornalistas, historiadores, pesquisadores e críticos do design. Não admira que "o Brasil foi e ainda é em muitos aspectos, um escravo das culturas americana e européia. Informações provenientes do estrangeiro tem sido sempre o primeiro aliado do designer gráfico brasileiro" (Thomas, 1987, p. 154).

Antes do aparecimento dos computadores pessoais e das telecomunicações digitais em rede, as informações geralmente vinham na forma de depoimentos e testemunhos visuais de viajantes que traziam de volta o mais recente livro ou revista de artes gráficas.
Assim," não é surpreendente encontrar livros de todo tipo e credo nas prateleiras dos designers brasileiros" (Thomas, 1987, p. 154).

Em conseqüência, persiste ainda hoje uma desvalorização generalizada de nosso passado gráfico, que também atinge a produção individual mais recente de nossos designers, pois muitos deles não procuram manter um portfólio organizado e atualizado de seus trabalhos passados, que pela ótica européia e americana eles próprios consideram "ultrapassados" e pouco representativos de um design inovador.

\section{A liberação do design pelo pós-moderno}

Na primeira metade do século $X X$, a retórica das manifestações visuais modernistas valoriza geralmente o novo, o puro, o original, o universal, buscando uma estética absoluta e elitista, num discurso veemente de verdades únicas. .

Por sua vez, na era pós-moderna atual, a retórica das imagens produzidas pela mídia tende a valorizar o efêmero, o eclético, o heterogêneo, a colagem, o híbrido, o tecnológico, caracterizando uma multidimensionalidade e flexibilidade estética condizentes com a era atual de relativismo e abundância de interpretações da realidade.

Representações pós-modernas deixaram de ser consideradas apenas simbólicas ou indiciais para serem, também e principalmente, construções icônicas. Pois tudo o que pode significar algo em termos visuais passa a ser considerada também "imagem" icônica, como linhas, diagramas, letras, traços, figuras, números, esquemas, cores, etc. Segundo Peirce, todo signo é primeiramente um ícone. Só depois de reconhecida sua imagem é que poderá tornar-se um índice. Eventualmente, se depois incorporar ainda uma norma, regra ou convenção, esse signo virá a ser um símbolo (signo comunitário), como os pictogramas internacionais. Portanto, todo e qualquer signo, na sua origem, é sempre e primeiramente um ícone.

\section{Na era pós-moderna afual, a retórica das imagens produzidas pela mídia tende a valorizar 0 efêmero, 0 eclético, 0 heterogêneo, a colagem, 0 híbrido, o tecnológico}

Agora se impõe considerar as dimensões retóricas das manifestações visuais mais representativas do modernismo e do pós-modernismo gráfico, para analisar mais objetivamente os processos de criação 
e de inovação no campo da comunicação gráfica. Devemos tentar identificar as características mais típicas das retóricas visuais modernistas e pósmodernistas que seus exemplos incorporam. Mas sem deixar de levar também em consideração os aspectos estéticos, factuais e convencionais das representações, para assim obter uma compreensão mais ampla da presença e função das dimensões retóricas nos imaginários da contemporaneidade (de designers, clientes e públicos envolvidos).

\section{Qualquer imagem gráfica é resultado de um processo de design visual, o que faz com que ambos estejam sempre mutuamente implicados}

Por isso as imagens deixaram de ter sua leitura e interpretação confiada as um número restrito de críticos "autorizados" para se popularizarem e se oferecerem à várias interpretações através das mídias, numa mixagem de referências visuais que era impensável na época em que se instituía o movimento tipográfico modernista, que como se sabe favorecia a simplicidade e a economia de meios no design da comunicação gráfica. $\mathrm{O}$ discurso contemporâneo do design pósmoderno cultiva uma visualidade que desconhece a divisão "modernista" entre representações de baixo valor (populares) e as magistrais (de elite), pois constroem proposições visuais híbridas, complexas, contraditórias, ambíguas, efêmeras e heterogêneas características que a modernidade, em suas versões racionalistas, quase sempre tentou reprimir em seus seguidores, através dos seus discursos, de seus manifestos e das propostas visuais (enfatizando quase sempre a legibilidade, a funcionalidade e a economia de meios que eles inspiravam).

\section{Características do design pós-moderno}

As características listadas a seguir foram compiladas como as mais típicas das imagens do design contemporâneo dito pós-moderno, como veiculadas pelas diversas mídias visuais de nosso tempo, para discussão durante um seminário sobre Imagem e Pósmodernidade, realizado em julho de 2002, por mim e pela Prof ${ }^{a}$ Maria Beatriz Rahde, pelo Programa de Pósgraduação em Comunicação da PUCRS.

Pensamos que a listagem dessas características ainda pode ser muito útil para discussões atuais sobre design e pós-modernidade. E que qualquer imagem gráfica é resultado de um processo de design visual, o que faz com que ambos estejam sempre mutuamente implicados. Vamos apresentar nossa listagem aqui como uma contribuição para futuras análises e complementações sobre a temática do design e da comunicação gráfica.

Essa listagem, que não exclui posteriores misturas de categorias de características, seria a seguinte:

- a imagem pós-moderna tende à multimídia, à mistura, à hibridação, empregando diversas possibilidades expressivas visuais (fotos, desenhos, pinturas, gravuras, modelos 3D, vídeo, etc) e/ou acionando vários outros sentidos simultaneamente à visão (audição, tato, olfato, etc);

- tende ao cultivo da ambigüidade, da indefinição, da indeterminação, da polissemia, usando artifícios como falta de indicações verbais (anúncios exclusivamente pictóricos), ou excesso de significantes no espaço e/ou no tempo (palimpsestos visuais, verbais e mistos, estáticos ou em movimento);

- ela visa ampliar ao máximo as suas possibilidades conotativas, procurando avidamente a participação ativa do espectador nesse jogo indecidível de interpretação, já que não há mais verdades únicas, permanentes, e universais, a serem propagadas ou encontradas, como mostrou Derrida;

- resulta muitas vezes da manifestação do efêmero, do transitório, do descartável, quando é transformada, entropicamente e ao acaso, pela ação dos agentes da natureza (descoloração por iluminação solar, oxidação por ar e umidade, decomposição pelo calor atmosférico, etc) ou interferências por agentes da cultura (vandalização por rasgos, pichações, superposições, fragmentações, demolições, etc);

- é tolerante com a imperfeição, da imprecisão, da poluição, e das interferências externas pós-produção (ruídos, deformações) pois essas expandem sua polissemia, originalidade e indeterminação;

- ela também aparece produzida por resultados criativos de jogos de significantes, sem regras muito fixas, que procuram incluir o espectador, valorizando os aspectos camaleônicos e interativos das representações (as mutações, os cambiamentos, as metamorfoses, as instabilidades), como podemos constatar, por exemplo, nas vinhetas da MTV ou em figuras caleidoscópicas;

- se apresenta muitas vezes com uma gramática esquizofrênica (incompleta, fragmentada, nãolinear) ou repleta de representações cifradas e enigmáticas, como produzidas por grupos sociais considerados desviantes e transgressores (loucos, drogados, vândalos, poetas) ou como representativas de estados oníricos (sonhos, pesadelos, devaneios); - resulta muitas vezes da différance (a diferença e o deferimento de sentido), em oposição aberta ou ironizando sutilmente cânones e estereótipos visuais da alta cultura, através da valoração de manifestações visuais engajadas de minorias sociais 
(de homosexuais, negros, índios, analfabetos, e similares);

- está ciente de seu status de simulacro, pois sabe, pelo pós-estruturalismo, que nenhuma representação tem acesso direto à realidade, sendo sempre uma interpretação ou invenção entre muitas possíveis (e quando prescinde de referenciais prévios dessa realidade);

- sua interpretação não segue sistemas de significados, mas sim é feita "caso a caso", de acordo com a pertinência das conotações sugeridas pelo contexto e pela vivência cultural do intérprete, e já antecipando que várias significações serão sempre possíveis, uma delas sendo escolhida como a mais relevante conforme as circunstâncias do momento;

- ela não se preocupa com sua pureza estilística ou em se apresentar como uma solução inédita de vanguarda, pois se sabe resultado da intertextualidade, da citação, da cópia, da hibridação de vários estilos diferentes disponibilizados por repertórios visuais de diferentes "histórias";

- é encontrada em alguns museus e galerias, mas se sente muito mais à vontade como representação veiculada por mídias visuais, a serviço da experimentação e do avanço tecnológico, do entretenimento, do consumo e da crítica bemhumorada;

- se opõe a todo tipo de geometrização, purificação e coordenação racionalista, pois quer ser fruto criativo do descontrole, da intuição, da improvisação, do inesperado, do aleatório, e ter ampla liberdade para misturar, hibridar, citar, incluir, quaisquer significantes que julgar oportunos, sem preocuparse em ser objetiva ou funcionalista ou inteligível.

\section{É possível e até mesmo necessário haver uma pluralidade de atitudes e estilos de design para os complexos problemas de comunicação da nossa era}

\section{Considerações finais}

Talvez a maior contribuição das soluções pósmodernas para o design gráfico da comunicação tenha sido mostrar que é possível e até mesmo necessário haver uma pluralidade de atitudes e estilos de design para os complexos problemas de comunicação da nossa era. Assim como não seria razoável implementar atualmente, um design desconstrucionista para a a sinalização visual de rodovias ou para a formatação de manuais de instrução e treinamento, também não seria adequado, em princípio, implementar atualmente um design modernista, monocromático e ascético, por exemplo, para revistas e capas de discos carnavalescos, ou para a programação visual de shows de rock direcionados a adolescentes cosmopolitanos ou à tribos urbanas.

O imaginário do design gráfico pós-moderno está voltado, pelo que se constata, para as possibilidades inventivas, artísticas e exploratórias de sua dimensão estética, o que torna essa prática altamente atraente e desafiadora para jovens comunicadores visuais.

Assim, uma nova geração de designers mundo afora está a explorar possibilidades e a confrontar problemas que surgem nessa prática libertária, mas complexa, de inovação da comunicação gráfica, e que incentiva o aparecimento gradual de uma diversidade de novos estilos gráficos peculiares, conferindo visibilidade concreta e presença política às mais diversas regiões, opiniões e minorias culturais do mundo. $\mathrm{Ou}$, pelo menos, é isso que desejaríamos acreditar estar acontecendo atualmente, com a ajuda do design pósmoderno $\square$ FAMECOS

\section{REFERÊNCIAS}

CAUDURO, Flávio Vinicius. Uma nova visualidade: as imagens da pós-modernidade. In: II Congresso Internacional de Design da Informação, Santo Amaro, São Paulo: SBDi \& Universidade Federal do Paraná, 2005.

ESCOREL, Ana Luisa. Corporate Identity. In: Print XLI:VI, Nov/Dec 1987, p. 80-89, p.156

RAHDE, Maria Beatriz Furtado. Imagem: estética moderna e pós-moderna. Porto Alegre: EDIPUCRS, 2000.

TABORDA, F . Popular Art, in Print XLI:VI, Nov/Dec 1987, p. 118-120

THOMAS, G. Theater and Film, in Print XLI:VI, Nov/ Dec 1987, p. 100-105, p.154-156

VALÉRIO, T. Music, in Print XLI:VI, Nov/Dec 1987, p. $90-99$ 